\title{
A TEORIA DOS JOGOS E O DIREITO: ENTENDENDO A APLICABILIDADE DA TEORIA DOS JOGOS AO DIREITO A PARTIR DOS JOGOS DE GUN JUMPING E DE INVESTIMENTO EM PROPRIEDADE INTELECTUAL
}

\section{GAME THEORY AND THE LAW: UNDERSTANDING THE APPLICABILITY OF GAME THEORY TO LAW FROM A STUDY OF GUN JUMPING AND INTELLECTUAL PROPERTY GAMES}

\author{
${ }^{1}$ Ananda Portes Souza \\ ${ }^{2}$ Andre Costa Ferreira de Belfort Teixeira
}

\section{RESUMO}

A teoria dos jogos vem sendo habitualmente utilizada como uma ferramenta de modelagem de decisões estratégicas, alcançando desde o campo da matemática, em que foi originalmente desenvolvida, até o campo da ciência econômica e da ciência política. Entretanto, ainda que os operadores do direito sejam, por definição, tomadores de decisão, a teoria dos jogos vem sendo raramente utilizada como ferramenta para auxiliar o tomador de decisão, no campo jurídico, de modo a permitir que esse conheça as decisões possíveis e suas potenciais consequências. $\mathrm{O}$ presente artigo pretende fazer um breve estudo da aplicabilidade da teoria dos jogos ao direito, como forma de torna-la uma ferramenta disponível para o operador do direito enquanto tomador de decisão. Para tanto, o artigo divide-se em três partes: na primeira, uma breve introdução sobre a teoria dos jogos é feita; na segunda parte, a teoria dos jogos é utilizada como ferramenta para compreensão dos jogos de investimento em pesquisa e desenvolvimento e proteção de propriedade intelectual; nas terceira parte, a teoria dos jogos é utilizada para justificar o instituto do gun jumping por meio do jogo do duopólio de Cournot.

Palavras-chave: Teoria dos jogos, Direito da concorrência, Propriedade intelectual, Gun jumping, Duopólio de cournot

\begin{abstract}
Game theory has been constantly used as a tool for modeling strategic decision making, reaching from mathematics, where the theory was developed, to economy and politics. However, even though legal professionals are essentially decision makers, game theory is rarely used as a tool to help the legal decision maker, so as to allow that decision maker to know possible decisions and potential outcomes. The present paper aims to develop a brief study of the applicability of game theory to law, as a means to set it as a tool available to legal professionals as decision makers. With that goal, the paper is divided into three parts: in the first part, a brief introduction to game theory is had; in the second part, game theory is used as a tool to understand the research and development investment and intellectual property protection games; in the third part, game theory is used to justify the existence of gun jumping protection through the Cournot duopoly game.
\end{abstract}

Keywords: Game theory, Competition law, Intellectual property, Gun jumping, Cournot duopoly

\footnotetext{
${ }^{1}$ Mestranda em Direito pela Universidade Federal de Minas Gerais - UFMG, Belo Horizonte, (Brasil). Advogada Associada do Humberto Theodoro Jr. Advogados Associados. E-mail: portesananda@gmail.com

${ }^{2}$ Mestrando em Direito pela Universidade Federal de Minas Gerais - UFMG, Belo Horizonte, (Brasil). Sócio da Belfort \& Moreira Advogados. E-mail: andrecbelfort@gmail.com
} 


\section{INTRODUÇÃO}

A teoria dos jogos é um ramo da ciência econômica que consiste na análise, realizada a partir de modelos matemáticos, das situações de interação estratégica - entendidas como aquelas situações em que participantes, sejam indivíduos ou organizações, reconhecem a interdependência mútua de suas decisões.

Esta disciplina examina situações nas quais um tomador de decisões tem que levar em conta a ação de outros indivíduos/organizações, para, assim, determinar qual seria a melhor decisão estratégica a ser por ele adotada. Segundo BIERMAN (2011), a teoria dos jogos "preocupa-se com o modo como indivíduos tomam decisões quando estão cientes de que suas ações afetam uns aos outros e quando cada indivíduo leva isso em conta"1.

Inicialmente aplicada ao campo da economia, a teoria dos jogos passou a ser empregada nas mais diversas searas: política, diplomacia, sociologia, estratégias militares, administração de empresas e também na esfera jurídica.

Segundo FIANI (2009), duas são as principais vantagens de se estudar a teoria dos jogos. A primeira consiste no fato de esta teoria auxiliar o entendimento teórico do processo de decisão de agentes que interagem entre si, a partir da compreensão da lógica da situação em que estão envolvidos, e a segunda decorre de ser ela um instrumento que auxilia o desenvolvimento da capacidade de raciocinar estrategicamente, explorando as possibilidades de interação dos agentes, possibilidades estas que, alerta o autor, "nem sempre correspondem à intuição",2.

Embora notabilizada com o artigo Non-Cooperative Games, de John F. Nash, Jr., publicado em 1951 no Annals of Mathematics 54, as raízes da teoria dos jogos remontam ao século XIX, com a publicação, em 1838, da obra Recherche sur les Principes Mathématiques de La Théorie des Richesses, de autoria do matemático francês Antoine Augustin Cournot, autor que será fundamental no estudo do jogo do Gun Jumping.

\footnotetext{
${ }^{1}$ Bierman, H. Scott, FERNANDEZ, Luiz. Teoria dos Jogos. 2a Edição. São Paulo, Pearson Prentice Hall, 2011, p. 6.

2 FIANI, Ronaldo. TEORIA DOS JOGOS. Rio de Janeiro: Elsevier, 2009, págs. 9 e 10.
} 
Embora a Teoria dos Jogos, enquanto ferramental teórico, tenha se difundido no estudo da matemática, da economia e, inclusive, da política, a utilização dessa teoria no campo do Direito ainda é muito incipiente, principalmente em face da dificuldade de modelagem de contextos jurídicos para uma série de variáveis a que se possa aplicar a teoria dos jogos.

Assim, o presente trabalho propõe dois casos distintos de aplicação da teoria dos jogos ao direito, principalmente como ferramenta para que se possa entender (e otimizar) a estrutura jurídica que tem como objetivo incentivar os agentes a tomar certas decisões. No primeiro caso, estuda-se uma modelagem de teoria dos jogos por meio da qual pretende-se incentivar o investimento em pesquisa e desenvolvimento, por meio de direitos de propriedade intelectual. No segundo caso, pretende-se estimular que agentes envolvidos em um ato de concentração não se sintam compelidos a realizar atos prematuros relativos à essa concentração, tendo em vista a reversibilidade da operação.

Mais importante, porém, que o estudo dos dois casos de modo individualizado é entender que a teoria dos jogos apresenta uma série de ferramentas que podem ser muito importantes na tomada de decisão dos operadores do direito - desde o momento do planejamento de políticas públicas ou de estruturas legislativas, alocação de direitos ou, até mesmo, no momento de uma decisão judicial. Com isso, pretende-se incluir esse modelo teórico como mais uma das várias ferramentas a auxiliar o operador do direito.

\subsection{A Proteção da Propriedade Intelectual}

A proteção aos direitos de Propriedade Intelectual é habitualmente justificada com base no estímulo à inovação, conforme reforçado, por exemplo, por Cooter e Ulen $(2008)^{3}$ e Lara $(2010)^{4}$. A restrição do acesso aos bens protegidos pela Propriedade Intelectual, portanto, seria justificada em um contexto em que os benefícios sociais da inovação no longo prazo

\footnotetext{
3 "When intellectual property rights are effectively enforced, the owner of a new computer chip or novel can use the power of exclusion to extract a price from other users. The price rewards the creator, which results in more innovations and faster growth - a form of "dynamic efficiency." (COOTER; ULEN, 2008, p.124).

4 "Na perspectiva da Análise Econômica do Direito, os institutos da propriedade intelectual [...] têm como objetivo e como limite os estímulos econômicos à criação das inovações. A propriedade intelectual decorre do sistema de eficiências econômicas e serve para estimular a produção de inovações". (LARA, 2010, p.114);
} 
seriam maiores do que os benefícios do acesso imediato e irrestrito no curto prazo ${ }^{5}$, incluído nesse contexto o estímulo que o agente inovador tem de disseminar o conhecimento que produziu, o que só ocorre com a garantia da proteção legal dessa inovação e da exclusividade mesmo em caso de disseminação do conhecimento ${ }^{6}$.

Para estimular a inovação, os direitos de Propriedade Intelectual têm também a função de ressarcir o titular pelo seu investimento em $P \& D$ - inclusive de projetos mal sucedidos - bem como garantir uma margem de lucro que torne o investimento futuro em P\&D uma atividade rentável. Para poder cobrir esses custos, é natural que o sistema de Propriedade Intelectual garanta certas restrições para que o mercado se comporte de forma diferente de um mercado com competição perfeita, pois neste último caso o custo de $\mathrm{P} \& \mathrm{D}$ incorrido pelo concorrente-inovador integraria a sua formação de preço, mas não a de um concorrentecopiador, que teria um incentivo muito maior para copiar do que o primeiro para inovar $^{7}$. Assim, a forma que se encontrou para estimular a inovação, garantindo que um concorrente-inovador consiga recuperar seus investimentos em $P \& D$, foi a criação de um sistema de proteção de Propriedade Intelectual que, ao conceder direitos exclusivos sobre a inovação, desestimule a imitação ${ }^{8}$. Esse sistema de proteção tem como consequência a possibilidade de que o titular dos direitos de Propriedade Intelectual possa agir como um monopolista formador de preços, determinando o preço que cobrará de acordo com o maior

\footnotetext{
5 "A ideia básica da proteção à propriedade intelectual, do ponto de vista da Análise Econômica do Direito, reside em que os benefícios (incentivo à inovação e ganhos remuneratórios do inventor/autor) do direito de exclusividade - ou do exclusivo - devem mais que compensar seus eventuais custos (restrição de acesso e de desenvolvimento e eventuais problemas concorrenciais). A perspectiva de auferição de lucros move o agente econômico. Caso contrário, o agente tende a não realizar a inovação." (SILVA, 2012)

6 "After making an innovation, disseminating it allows more people to enjoy its advantages. Intellectual property rights can also increase dissemination. Without property rights, the innovator may try to keep the innovation secret in order to profit from it. [...] With effective intellectual property rights, however, the innovator need not fear that others will steal the innovation. Instead of keeping it secret, the owner can disseminate it and charge fees for its use, such as licensing fees for patents or performance fees for plays. Replacing Secrecy with property increases dissemination, which results in wider use-an increase in "static efficiency." (COOTER; ULEN, 2008, p.124-125)

7 "Intellectual property is often very costly to create, but the costs of creation, being invariant to output, are fixed costs once incurred. In contrast, the costs that vary with output, which is to say the costs incurred in actually providing the intellectual property to consumers, often are very low, at least relative to the fixed costs; [...] But a price above marginal cost, though necessary to enable the producer of the intellectual property to recoup fixed costs (unless those costs are subsidized), not only will deflect some potential purchasers to substitutes that cost society more to produce on a quality-adjusted basis, but it will also induce inefficient entry by firms that do not have to incur heavy fixed costs, as is commonly the case when a new entrant can free ride on the investment made by incumbent firms." (POSNER, 2005);

8 "De certa forma, o sistema de proteção à propriedade intelectual funciona como um mecanismo de premiação à empresa inovadora (schumpeteriana e assumidora de riscos) e, ao mesmo tempo, de penalização para as empresas tradicionais (imitadoras)." (CARRARO, 2005, p.59)
} 
retorno possível, afastando-se do preço de equilíbrio de mercado ${ }^{9}$. O titular, portanto, é livre para formar o preço sem necessariamente considerar o maior retorno em termos de riqueza social $^{10}$, conforme Lara:

A cobrança de preços monopolistas gera uma quantidade de peso-morto, que consiste em perda social, que não é apropriada pelo monopolista. Ou seja, é perda total de riqueza, devendo ser eliminada pela estrutura do direito, porque causa ineficiência. (LARA, 2010, p.114)

A consequência da determinação de um preço com características monopolistas é a existência de uma demanda potencial que não tem acesso aos bens protegidos - denominada por Lara (2010) de "peso-morto". Esse peso-morto é sintoma de uma ineficiência no sistema de atribuição de direitos de Propriedade Intelectual. A riqueza relativa ao retorno em potencial da demanda não atendida é perdida, não sendo apropriada pelo titular dos direitos, e nem se revertendo no benefício do uso dos bens tutelados pela Propriedade Intelectual por parte daqueles interessados que estejam fora da demanda projetada pelo titular e alcançada pelo preço por ele estabelecido.

A partir dessa distorção, Lara (2010) sugere:

A utilização do objeto da proteção intelectual por aqueles que estão fora da demanda projetada possibilita a eliminação do peso-morto e não implica a diminuição do valor da propriedade do monopolista, sendo situação de eficiência paretiana (Ótimo de Pareto).

[...] A função social da propriedade intelectual, ainda que não possa impedir a cobrança de preços monopolistas, autoriza a obtenção dos proveitos do objeto da propriedade intelectual por aqueles que não têm condição de pagar por isso, ou seja, estão fora da demanda projetada. (LARA, 2010, p.114-115)

Tal solução, entretanto, aparenta confrontar-se com o fundamento básico da Propriedade Intelectual de incentivo à inovação. Admitir a utilização não autorizada de bens protegidos por direitos de Propriedade Intelectual poderia significar um desestímulo à inovação, uma vez que o titular deixaria de ter a exclusividade sobre a exploração de seus direitos no âmbito da demanda não projetada. Ou seja, ao optar por um preço - que poderia

\footnotetext{
9 "A valuable invention creates a better product or a better way to make an old product. If the invention has no close substitutes, granting a patent or copyright creates "monopoly power," which means that the seller can raise the price." (COOTER; ULEN, 2008, p.125)

${ }^{10}$ "To maximize profits, the owner-monopolist sets the user fee too high for social efficiency, so use is too low. Thus, intellectal property law results in less dissemination of an innovation than required for static efficiency." (COOTER; ULEN, 2008, p.125)
} 
ser determinado livremente com base nas características monopolistas do mercado de Propriedade Intelectual - o titular estaria efetivamente abrindo mão da exclusividade de exploração em relação aos consumidores que não tivessem condições de arcar com esse preço, e que estariam, portanto, além da demanda projetada.

No presente trabalho, pretende-se confrontar a sugestão de Lara (2010) com o fundamento de estímulo à inovação que sustenta a proteção de direitos de Propriedade Intelectual, por meio de um estudo do modelo do jogo de inovação proposto por Carraro (2005).

Desse confronto se pretende deduzir qual o impacto esperado no incentivo à inovação no caso da utilização livre dos direitos de Propriedade Intelectual por agentes não incluídos na demanda projetada inicial.

Nesse contexto, a Teoria dos Jogos será utilizada para modelar um jogo que permita a visualização do impacto do modelo de acesso aos bens protegidos por Propriedade Intelectual nos incentivos e recompensas dos titulares desses direitos. A partir dessa modelagem, poder-se-á chegar a algumas conclusões acerca do incentivo à inovação promovido pela proteção à Propriedade Intelectual.

\subsection{O Jogo de Investimento em P\&D}

Para que se possa entender o estímulo que uma determinada empresa tem para investir ou não investir em Pesquisa e Desenvolvimento $(P \& D)$, Carraro (2005) propõe um jogo entre duas empresas concorrentes. Esse jogo - uma variação do dilema do prisioneiro - pode ser descrito da seguinte forma:

Certamente, num ambiente no qual a patente é perfeitamente protegida nenhuma firma possui qualquer interesse que a sua rival vença a disputa pela inovação. Mas, quando a proteção fornecida pela patente não for respeitada, a imitação passa a ser uma ação possível de ser tomada por qualquer firma que esteja no mercado. Agindo desta forma (imitando) a firma poderá ter acesso a nova tecnologia sem ter incorrido nos custos associados com a atividade de $\mathrm{P} \& \mathrm{D}$ e sem ter que pagar ao inovador pelo direito de uso do novo conhecimento, além de não sofrer os riscos naturais ligado a esta atividade. Nesta situação, as duas firmas estão num Dilema dos Prisioneiros. (CARRARO, 2005, p.50) 
Prossegue o autor, quanto aos efeitos do sistema de Propriedade Intelectual na decisão de investir em P\&D:

O modelo de D'Aspremont \& Jacquemin (1988) considera uma indústria com duas firmas disputando um duopólio do tipo de Cournot. O jogo possui dois estágios não-cooperativos. No primeiro estágio, as firmas decidem quanto investir em P\&D na busca de uma nova tecnologia que reduza o custo de produção e, no segundo estágio, elas concorrem no mercado pelas quantidades vendidas. $[\ldots]$

$\beta$ representa a externalidade do investimento em $P \& D$ da empresa i na função custo da empresa j. Quanto mais a empresa i investir em P\&D, menor será seu custo de produção, mas além disto, o investimento da empresa $j$ também pode diminuir o custo da empresa i. Para isto acontecer, basta que $\beta$ seja maior que zero.

$\mathrm{O}$ valor de $\beta$ irá depender diretamente da eficiência do sistema de proteção à propriedade intelectual. Caso a estrutura legal e institucional [...] esteja organizada de forma a garantir os direitos do inovador a um baixo custo, impossibilitando a cópia da inovação pelas firmas rivais, $\beta$ terá um valor próximo de $0 .[\ldots]$

Portanto, um valor de $\beta=0$ representaria a ausência de externalidade provocada, por exemplo, pela presença de um perfeito sistema de proteção à inovação que impossibilitasse a qualquer das firmas se apropriar do conhecimento gerado pela sua rival. No outro extremo, $\beta=1$, todo o conhecimento gerado por uma das empresas pode ser perfeitamente apropriado, sem nenhum custo, pela sua rival (imitação). Logo, tem-se que o grau de proteção à propriedade intelectual pode ser obtido por $(1-\beta)$. (CARRARO, 2005, p.51-52)

Tal jogo apresenta um equilíbrios de Nash dependentes da proteção legal conferida às inovações no contexto do jogo. Se há uma proteção forte para direitos de Propriedade Intelectual $(\beta<0,5)$, então as empresas jogam um jogo de patent race para determinar quem consegue alcançar a inovação primeiro, e o equilíbrio de Nash é deslocado para ambas investirem em P\&D.

A partir da equação que encontra para o cálculo do Equilíbrio de Nash no Jogo do Investimento em P\&D, Carraro (2005) faz a seguinte simulação de equilíbrio em um ambiente com forte proteção à Propriedade Intelectual $(\beta=0,1)$ :

FIRMA 2

\begin{tabular}{|c|c|c|}
\hline & Com P\&D & Sem P\&D \\
\hline Com P\&D & 6,$97 ; 6,97$ & 2,$72 ;-0,35$ \\
\hline
\end{tabular}


FIRMA 1

\begin{tabular}{|l|l|l|}
\hline Sem P\&D & $-0,35 ; 2,72$ & 1,$36 ; 1,36$ \\
\hline
\end{tabular}

Tabela 1 - Matriz de Ganhos com Proteção Forte

Em um ambiente com forte proteção à Propriedade Intelectual $(\beta=0,1)$, portanto, há também um forte estímulo à inovação, e o equilíbrio de Nash se deslocaria para um ambiente de investimento mútuo em P\&D.

Entretanto, em um contexto de proteção fraca $(\beta>0,5)$, o ganho em potencial de uma empresa que invista em P\&D é diluído pelo curto tempo em que a mesma terá um ganho de mercado em decorrência da inovação, já que a concorrente poderá facilmente adotar uma estratégia de imitação da inovação.

A partir da mesma equação de cálculo do Equilíbrio de Nash no Jogo do Investimento em P\&D, Carraro (2005) faz outra simulação, agora para equilíbrio em um ambiente com baixa proteção à Propriedade Intelectual $(\beta=0,9)$ :

FIRMA 2

\begin{tabular}{|c|c|c|c|}
\hline \multirow{3}{*}{ FIRMA 1} & & Com P\&D & Sem P\&D \\
\hline & Com P\&D & 2,$55 ; 2,55$ & $-3,9 ; 10,02$ \\
\hline & Sem P\&D & 10,$02 ;-3,9$ & 5,$05 ; 5,05$ \\
\hline
\end{tabular}

Tabela 2 - Matriz de Ganhos com Proteção Fraca

Em um novo ambiente, agora com baixa proteção à Propriedade Intelectual $(\beta=0,9)$, não haveria estímulo à inovação, e o equilíbrio de Nash se deslocaria para um de ausência de investimento em P\&D.

Nesse último caso, a rapidez com que se espera que um concorrente possa reproduzir a inovação - eliminando, portanto, qualquer vantagem competitiva da concorrente-inovadora - torna a escolha por não investir em P\&D uma estratégia estritamente dominante ${ }^{11}$, já que é a melhor estratégia a ser adotada independente da estratégia adotada pela concorrente. Ambas

\footnotetext{
11 “Uma estratégia estritamente dominante para um jogador é aquela que domina estritamente todas as outras estratégias desse jogador. Um jogador racional adotará uma estratégia estritamente dominante sempre que ela existir." (BIERMAN E FERNANDEZ, 2011, p.9)
} 
empresas optarão por não investir em $\mathrm{P} \& \mathrm{D}$, aguardando pela inovação alheia, que apenas acontecerá espontaneamente (sem ser fruto de uma política de P\&D), e que será imediatamente copiada pelas demais competidoras.

Há, portanto, uma relação direta entre o grau de proteção à Propriedade Intelectual e a melhor estratégia a ser adotada por empresas competidoras - se investir em P\&D ou imitar a inovação alheia. Carraro (2005) conclui que, em um dado cenário, um valor máximo de 0,5 para a variável $\beta$ - e que significa, portanto, uma proteção à Propriedade Intelectual de valor mínimo 0,5 - deslocará o equilíbrio de Nash para uma situação de investimento mútuo em

$\mathrm{P} \& \mathrm{D}$ e, portanto, um cenário favorável à inovação ${ }^{12}$. Consequentemente, no caso de valores de $\beta$ superiores a 0,5 o equilíbrio de Nash para as empresas é uma situação de não investimento comum e, portanto, um cenário contrário à inovação.

\subsection{O Jogo da Proteção da Propriedade Intelectual}

O que é interessante ressaltar no jogo proposto por Carraro (2005) é que a variável $\beta$ é um fator externo ao jogo; ou seja, no momento em que os jogadores decidem sua estratégia de investimento, pressupõe-se que ambos conhecem o valor de $(1-\beta)$ - e também que esse valor seja estável. Entretanto, se estamos diante de uma investigação sobre a possibilidade de alteração ou não do valor de $(1-\beta)$, ou seja, do grau de proteção à Propriedade Intelectual e, portanto, do próprio incentivo dado às empresas, podemos pressupor um jogo anterior, em que o valor de $(1-\beta)$ não é, ainda, conhecido.

Carraro (2005) desenvolveu seu trabalho em um contexto de análise do impacto da entrada em vigor da então "nova Lei de Patentes" (Lei n 9.279/96), de modo que a situação fática vivenciada pelos empresário da época era de uma mudança significativa no valor da variável $(1-\beta)$ para um valor então desconhecido. Uma vez que o processo de tomada de decisão estratégica de investimento ou não em P\&D depende do valor de $(1-\beta)$; e que esse valor pode ser alterado pelo estado, então a decisão do Estado de estabelecer um sistema de proteção à Propriedade Intelectual é, por si só, uma jogada que pode definir as estratégias futuras dos demais jogadores:

12 "Utilizando estes valores obteve-se que a firma i passará a responder a um aumento no investimento em $P \& D$ da firma $j$, com um aumento no seu próprio investimento em $P \& D$ para todo $\beta<0,5$. Ou seja, a partir de um grau de proteção à propriedade intelectual $(1-\beta)>0,5$, a função de reação da firma i torna-se positiva." (CARRARO, 2005, p.54) 
Desta forma, caso haja interesse político-econômico em incentivar as firmas a se engajarem num esforço de $\mathrm{P} \& \mathrm{D}$, desenvolvendo novas tecnologias, as instituições políticas devem agir por meio da ação legal (introduzindo um eficiente sistema de proteção à patente), transformando os custos de transação envolvidos nas estratégias. [...] Na realidade, o sistema legal de patentes irá redefinir o próprio dilema estratégico das firmas. [...]

A introdução de um sistema mais eficiente de proteção à patente no setor farmacêutico, ao modificar os custos de transação envolvidos na adoção da estratégia copiar, coloca as empresas farmacêuticas nacionais num novo nódulo de decisão: investir em P\&D ou licenciar. (CARRARO, 2005, p.61)

Nesse último caso, podemos enxergar o Estado como um super-jogador, que estabelece o valor dessa variável $(1-\beta)$ tendo em vista o interesse político no incentivo à inovação. Assim, seja por meio da atuação do poder legislativo, estabelecendo normas sobre Propriedade Intelectual; ou por meio do poder judiciário, optando por reconhecer a posteriori a ausência de ilicitude civil ou penal a partir do uso não autorizado de bens protegidos por Propriedade Intelectual em determinados contextos - como sugerido por Lara (2010) - o Estado seria um jogador sui generis em um jogo anterior ao Jogo do Investimento em P\&D - que pode ser denominado Jogo da Proteção da Propriedade Intelectual.

Nesse novo jogo o Estado tomaria a primeira decisão acerca de quanto proteger (ou não proteger) a Propriedade Intelectual. A partir dessa decisão, que constituiria o valor de (1 $\beta)$, as empresas-jogadoras poderiam, por sua vez, decidir quanto investir em P\&D com base no retorno esperado de seu investimento.

Utilizando-se os valores de $\beta$ e as recompensas encontradas por Carraro (2005), e considerando que as recompensas serão as mesmas independentes da firma que tomar a decisão (por ser um jogo simétrico) o Jogo da Proteção da Propriedade Intelectual poderia ser desenvolvido da seguinte forma: 


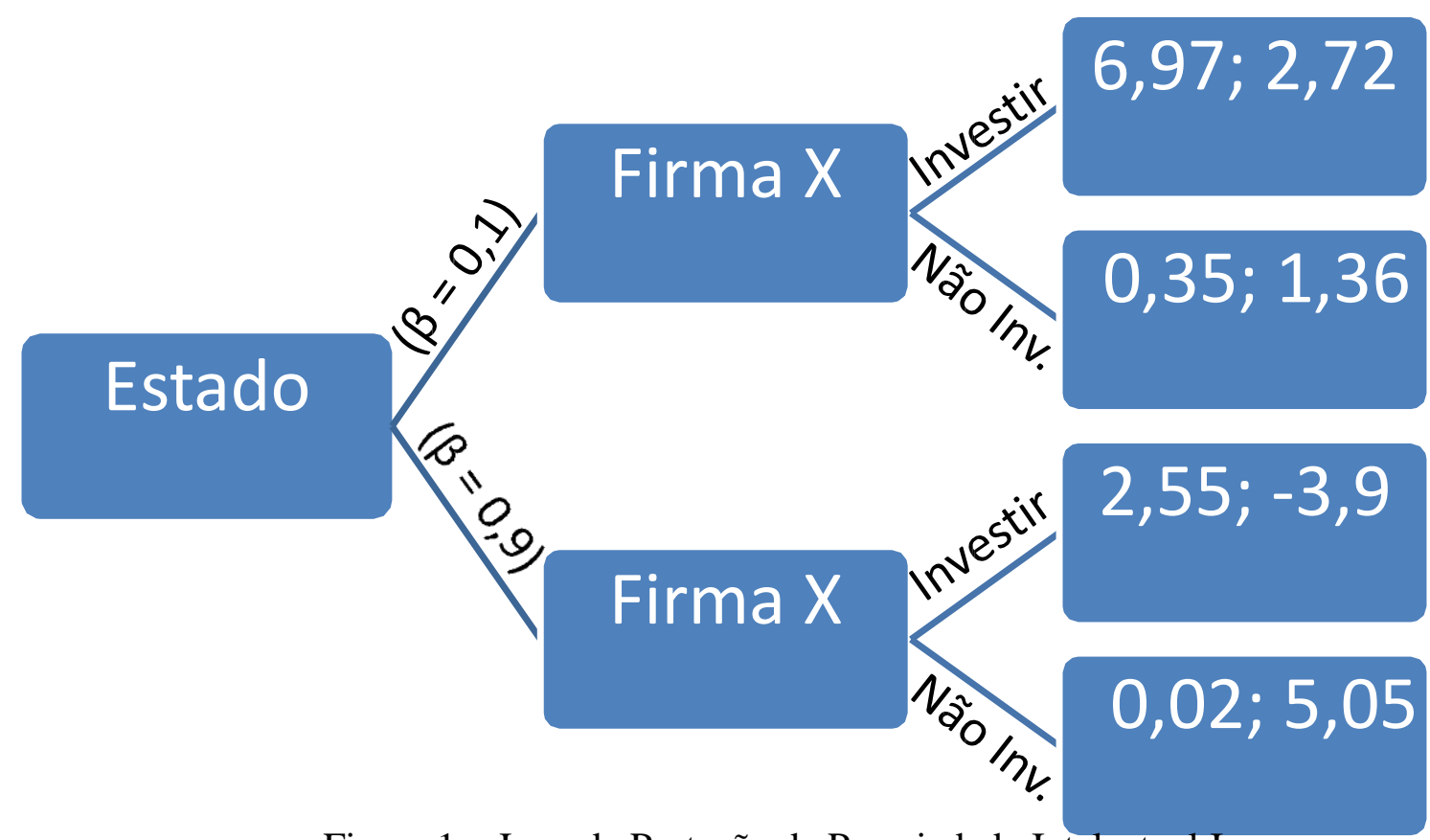

Figura 1 - Jogo da Proteção da Propriedade Intelectual I

É nesse último jogo que podemos vislumbrar, de forma mais direta, a relação entre o grau de proteção conferido à Propriedade Intelectual e o incentivo privado a investir em inovação. Uma vez que o Estado determine o grau de proteção (representado, em valor inversamente proporcionais, por $\beta$ ) é possível para o agente determinar se a melhor estratégia é ou não investir em P\&D. Por se tratar de um jogo simétrico, o jogo é o mesmo tanto para a Firma 1 quanto para a Firma 2, e as estratégias dominantes são, respectivamente, investir e investir para $\beta=0,1$; e não investir e não investir para $\beta=0,9$.

\subsection{Ausência parcial de Proteção e Licença Compulsória e o Incentivo à Inovação}

Uma vez que se tenha estabelecido a árvore de jogo (Figura 1) proposta no item anterior, pode-se efetivamente questionar: a ausência de proteção aos direitos de Propriedade Intelectual relativamente à demanda não-projetada pelo titular desses direitos tem o condão de desestimular a inovação?

Nesse caso, conforme exposto por Lara (2010), o retorno esperado pelo titular, quando o mesmo determinou o preço que cobraria pelo uso dos direitos de sua titularidade, não é alterado. Ou seja, do ponto de vista da teoria dos jogos, as recompensas permanecem as 
mesmas, já que as exceções propostas à exclusividade sobre a Propriedade Intelectual não impactam a demanda projetada pelo titular.

Ora, se as recompensas são mantidas, com base nos mesmos investimentos, então não se pode prever uma diminuição no investimento em $P \& D$. Uma vez que se pressupõe que os jogadores são racionais e que isso implica que eles vão sempre realizar suas escolhas de modo a maximizar o retorno esperado, então espera-se que um jogador racional mantenha sua estratégia anterior, por ser a que traz mais retorno. Nesse mesmo sentido concluíram Lara (2010) e Silva (2012), uma vez que os beneficiários dessa exceção aos direitos de Propriedade Intelectual não significariam, mesmo em um ambiente de proteção absoluta dos direitos de Propriedade Intelectual, receita adicional para o titular desses direitos.

É decorrência lógica, então, que os incentivos encontrados no jogo exposto na Figura 1 permanecerão os mesmos, mantendo-se também a estratégia ótima do jogador ao optar por investir em P\&D num cenário de $(1-\beta)>0,5$. Considerando a equação proposta por Carraro (2005), não há alteração no $\beta$ e, portanto, nos resultados obtidos a partir da aplicação daquela equação.

\subsection{Pressão pela Discriminação de Preços}

A possibilidade de institucionalização de uma política que admita o uso não autorizado de direitos de Propriedade Intelectual nos moldes propostos por Lara poderia representar, também, uma pressão de mudança de paradigma por parte do titular dos direitos, sob uma perspectiva de interesse na maximização dos lucros desse titular.

Ainda que os incentivos propriamente ditos não sejam alterados pela possibilidade do uso não autorizado já descrito, do ponto de vista empresarial a riqueza gerada e não apropriada pelo titular poderia significar uma oportunidade perdida de maximização de lucros.

No paradigma anterior, da determinação de um preço fixo, o titular projetava os lucros que teria e tinha uma previsão razoável de retorno. Nesse caso, a demanda não projetada não representava uma perda de riqueza para o titular, pois não havia apropriação por ninguém da riqueza social não aproveitada. No novo paradigma, o titular pode identificar, 
objetivamente, a apropriação direta da riqueza social que ele não aproveitou, e embora isso não represente uma perda de faturamento nem uma alteração na política de incentivos, representa uma perda de oportunidade; no novo paradigma, a riqueza não apropriada pelo titular é apropriada socialmente com retorno zero para esse titular.

Nessa nova perspectiva, o titular, ao identificar que a riqueza de que ele não se apropriar será apropriada socialmente com retorno zero, pode optar por um modelo de negócio que inverta isso, num processo de reestruturação dos modelos de remuneração já identificado por Silva $(2012)^{13}$. Uma vez que o titular é um tomador de decisões racional, os retornos envolvidos com a escolha de (i) não-apropriação dessa riqueza ou de (ii) apropriação da riqueza por meio de uma política de discriminação de preços levam, racionalmente, a uma escolha pela segunda estratégia, em detrimento da primeira. Nesse ponto, cumpre ressaltar o alerta de Silva (2012):

Levando em conta tal concepção, não é dado na aplicação da legislação antitruste, especialmente no controle preventivo dos atos de concentração, impor modelos de negócio. As restrições estruturais ou comportamentais impostas pelos órgãos antitruste devem buscar tão somente o controle do poder de mercado a ser exercido por empresas em concentração, salvaguardando um cenário de competição possível. Não se deve impor, com a justificativa de controle, um ambiente de negócio desejável para aquele segmento da economia. De novo: protege-se a concorrência, não um modelo de negócio concorrencial. É uma sintonia fina complexa, mas indispensável. [...]

Não deve impor ou ir contra modelos de negócios, mas deve advogar a criação ou fomento de ambientes mais competitivos. Em tais ambientes, as empresas são livres para atuar e desenvolver modelos alternativos. (SILVA, 2012)

Embora esse alerta seja relativo ao Direito da Concorrência, a conclusão é mais do que aplicável ao presente caso: não se trata de forçar, aos agentes, uma conduta específica desejável (uma discriminação de preços concorrencialmente legítima), mas sim de fomentar um ambiente mais competitivo e eficiente, em que o agente pode escolher por apropriar-se da riqueza não projetada ou dela abrir mão.

\footnotetext{
13 “A nova economia está calcada no modelo de negócio digital. [...] A rede mundial de computadores redefine completamente a forma de distribuição e acesso aos produtos desenvolvidos e igualmente os esquemas de remuneração." (SILVA, 2012)
} 
Ademais, do ponto de vista concorrencial, é possível para o titular dos direitos estabelecer critérios de discriminação de preços sem incorrer no ilícito previsto no inciso $\mathrm{X}$ do $\S 3^{\circ}$ do artigo 36 da Lei 12.529/11, como admitido por Cordovil (2012, p. 113) e pelo próprio CADE, no Anexo I da Resolução 20/99 ${ }^{14}$ e em seu Guia Prático ${ }^{15}$.

A escolha, portanto, por uma política de possibilidade de uso não-autorizado pode, em um segundo momento, levar as empresas-jogadoras a optar por modelos de negócios que incluam, quando possível, a cobrança com legítima discriminação de preços. Tal escolha também não representaria um afastamento do Ótimo de Pareto, pois haveria uma transferência de riqueza entre o e titular e a sua nova demanda, e não mais uma situação de riqueza não apropriada. Essa circunstância não apenas garantiria acesso potencialmente universal aos bens protegidos pela Propriedade Intelectual como, também, permitiria ao titular apropriar-se do máximo de retorno possível de seus direitos de Propriedade Intelectual, o que representaria um sistema de recompensas ainda mais positivo em prol de políticas de investimento em inovação.

\subsection{O Sistema de Análise Prévia dos Atos de Concentração Instituído pela Lei 12.529 de 2011}

A Lei $n^{\circ} 12.529$ de 30 de Novembro de 2011 instituiu no Brasil o denominado sistema de análise prévia dos atos de concentração, à luz do qual, até que a operação seja aprovada, as partes são vistas pela autoridade concorrencial como empresas separadas, e como tal devem agir.

Primeiramente é necessário definir o que deve ser entendido por "ato de concentração". Esta definição é dada pelos quatro incisos do artigo 90 da nova Lei Antitruste, que, em síntese, preveem constituírem atos de concentração a fusão de duas ou mais empresas para a constituição de uma nova sociedade; a aquisição por uma empresa de participação societária ou de ativos (tangíveis ou intangíveis) de outra, e a celebração de contratos, consórcios associativos (exceto aqueles destinados à participação em licitações) ou joint

\footnotetext{
${ }^{14}$ Resolução n²0/99 do CADE, p.5. Disponível em: http://www.cade.gov.br/upload/Resolu\%C3\%A7\%C3\%A30\%20n\%C2\%BA\%2020,\%20de\%209\%20de\%20junho\% 20de\%201999.pdf Acessada em 31/05/2014

${ }^{15}$ Guia Prático do CADE, p.39. Disponível em: http://www.cade.gov.br/publicacoes/guia_cade 3d 100108.pdf Acessada em 30/05/2014
} 
ventures. É possível extrair das hipóteses legais que a concentração de empresas é todo ato de associação empresarial que importe a substituição de órgãos decisórios (inicialmente independentes) por um sistema unificado de controle empresarial.

Contudo, nem todos os atos de concentração que subsumem ao art. 90 da Lei 12.529/11 deverão ser submetidos à análise da Conselho Administrativo de Defesa da Concorrência - CADE. Para tanto tais atos deverão também se amoldar aos índices de jurisdição estabelecidos no art. 88 do mesmo diploma, o qual, com as alterações promovidas pela Portaria Interministerial $\mathrm{n}^{\circ} 994$ de 30 de Maio de 2012, prevê que deverão ser submetidos ao CADE os atos de concentração em que cumulativamente pelo menos um dos grupos envolvidos tenha registrado, no último balanço, faturamento bruto anual ou volume de negócios total no País, no ano anterior à operação, equivalente ou superior a $\mathrm{R} \$$

750.000.000,00 (setecentos e cinquenta milhões de reais), e pelo menos um outro grupo tenha, no mesmo sentido, registrado valor superior a $\mathrm{R} \$ 75.000 .000,00$ (setenta e cinco milhões de reais).

O art. 88 da Lei Antitruste ainda prevê, ao longo de seus parágrafos, que o controle dos atos de concentração será prévio $\left(\S 2^{\circ}\right)$, que tais operações não poderão ser consumadas antes de apreciadas pelo CADE, sob pena de aplicação de nulidade, aplicação de multa pecuniária, e abertura de processo administrativo para imposição de sanções por infrações à ordem econômica $\left(\S 3^{\circ}\right)$, e, por fim, que até a decisão final da autarquia, deverão ser preservadas as condições de concorrência entre as empresas envolvidas $\left(\S^{\circ}\right)$.

Esclarecendo o alcance de tais dispositivos, o art. 108 da Resolução ${ }^{\circ}{ }^{1}$, de 29 de maio de 2012 (Regimento Interno do CADE - RICADE) prevê, em seus parágrafo $2^{\circ}$ que as partes deverão manter as estruturas físicas e as condições competitivas inalteradas até a apreciação final do CADE, sendo vedadas, inclusive, quaisquer transferências de ativos e qualquer tipo de influência de uma parte sobre a outra, bem como a troca de informações concorrencialmente sensíveis que não seja estritamente necessária para a celebração do instrumento formal que vincule as partes.

\subsection{O Instituto do Gun Jumping}


Nesse contexto legal se insere a prática denominada nos Estados Unidos da América de Gun Jumping ${ }^{16}$, que consiste na conduta anticompetitiva de consumar o ato de concentração de forma prematura, isto é, antes da devida autorização da autoridade anticoncorrencial, violando, portanto, o dever se aguardar a aprovação da autoridade antitruste para realizar o negócio jurídico ${ }^{17}$.

MARTINS (2012) define Gun Jumping como "a teoria que se presta a analisar a suposta conduta anticompetitiva praticada em sede de controle de estruturas, decorrente, sobretudo, da troca indevida de informações e/ou da integração prematura entre as empresas em processo de concentração econômica" ${ }^{\text {18 }}$.

É cediço que a consumação prematura dos atos de concentração pode ocorrer de diversas formas, mencionadas exemplificativamente no citado art. 108 do Regimento Interno do CADE, a saber: por meio da transferência de ativos, através do exercício de qualquer tipo de influência de uma parte sobre a outra e pela troca de informações comercialmente sensíveis.

Ao estabelecer vedações à conduta das partes durante o período de análise do ato de concentração o legislador intenta, nos termos do $\$ 4^{\circ}$ do art. 88 da Lei 12.529 , preservar as condições de concorrência entre as empresas envolvidas, e, em última instância, promover a livre concorrência e a defesa dos consumidores, como dispõe o art. $1^{\circ}$ do mesmo diploma legal, e com supedâneo nos incisos IV e V do art. 170 da Constituição da República de 1988, que estabelece como princípios da ordem econômica a livre concorrência e a defesa do consumidor, respectivamente.

\subsection{O 'Duopólio de Cournot'}

O que se propõe demonstrar é que as vedações impostas pela Lei 12.529 de 2011 às condutas das partes envolvidas em um ato de concentração, durante o período compreendido entre o protocolo da notificação do ato de concentração e a respectiva aprovação da operação,

\footnotetext{
${ }_{16}^{16}$ Expressão que pode ser traduzida como "queimar a largada".

${ }^{17}$ CORDOVIL, Leonor (et al). Nova Lei de Defesa da Concorrência Comentada - Lei 12.529 de 30 de novembro de 2011. São Paulo: Editora Revista dos Tribunais, 2011.

${ }_{18}$ MARTINS, Amanda A. L. Gun Jumping no Brasil: estudo comparativo e diretrizes para a adoção de regras de notificação prévia pelo Novo CADE. Revista do IBRAC. São Paulo, n. ${ }^{\circ} 22$, p. 58 e 59.
} 
se justificam diante da finalidade da Lei de promover a livre concorrência e a defesa dos consumidores.

Para tanto será utilizado o instrumental oferecido pela teoria dos jogos, a partir do qual é possível demonstrar, de forma matemática que a coordenação entre as partes altera seu comportamento no mercado, tendendo a provocar o aumento do preço de venda de seus produtos, com o aumento do lucro destes agentes econômicos, em detrimento da livre concorrência e dos consumidores.

O matemático francês Antoine Augustin Cournot, em seu livro Recherche sur les Principes Mathématiques de La Théorie des Richesses, desenvolveu o modelo denominado Monopólio de Cournot, que analisa uma situação hipotética em que duas empresas produzindo um bem homogêneo devem decidir simultaneamente sobre a quantidade que cada uma irá produzir, ciente que a quantidade produzida pela outra empresa afetará diretamente seus lucros.

O Equilíbrio de Cournot é a melhor resposta de uma empresa dada a estratégia da outra, sendo, assim, a quantidade que uma empresa irá produzir, dada a produção esperada da outra, para maximizar seus lucros.

Entendemos que esta hipótese pode se verificar em um ato de concentração horizontal, realizado entre agentes, que chamaremos de Empresa A e Empresa B, que atuam no mesmo mercado relevante material e geográfico, fabricando produtos homogêneos e disputando o mesmo mercado. Parte-se, ainda, da premissa de que ambas as empresas buscam maximizar seus lucros, sendo esta a recompensa por ambos os jogadores.

A modelagem do jogo é proposta por FIANI ${ }^{19}$, com base no modelo clássico do duopólio de Cournot. Inicialmente considera-se que o preço de mercado é dado por uma função de demanda linear do tipo: $p=100-q_{1}-q_{2}$, em que $q_{1}$ é a quantidade produzida e vendida pela Empresa 1 e $q_{2}$ é a quantidade produzida e vendida pela empresa 2.

\footnotetext{
${ }^{19}$ FIANI, Ronaldo. TEORIA DOS JOGOS. Rio de Janeiro: Elsevier, 2009, págs. 123 e ss.
} 
O autor demonstra que, caso estas empresas formem uma coalização, coordenando suas atividades, o que pode se dar seja em função da consumação prematura de um ato de concentração, seja em razão de um cartel propriamente dito, é possível calcular a quantidade a ser produzida por cada empresa que maximizará os lucros, que resulta em 24 unidades, de modo que a produção do cartel será de 48 unidades. Nesta hipótese, o preço de mercado será de $\mathrm{R} \$$ 52 por unidade, e o lucro de cada Empresa será de R \$ 1.152.

Em seguida, expõe qual seria a quantidade produzida caso essas empresas não coordenassem suas atividades. Considerando que as Empresas não tiveram acesso às informações concorrencialmente sensíveis uma da outra, não tendo formado uma coalizão, a quantidade que cada empresa irá produzir no equilíbrio de Cournot é de 32 unidades. O preço de mercado, por consequência, será de R \$36, e o lucro de cada Empresa somará R \$ 1.024.

Com esse exemplo o autor demonstra matematicamente o efeito da coordenação, qual seja: elevar o preço de venda e reduzir a quantidade produzida. Com efeito, na hipótese de não haver coordenação entre as empresas, o preço de venda é de $\mathrm{R} \$ 24$, ao passo de que quando esta se verifica, este valor passa a ser de $\mathrm{R} \$ 32$, apresentando, assim, uma elevação de mais de $30 \%$.

Tem-se, assim, a comprovação direta do impacto que a coordenação e o acesso a informações sensíveis pode produzir no mercado, elevando o preço dos produtos.

\subsection{O Gun Jumping e o Duopólio de Cournot - Conclusões Preliminares}

O que se percebe é que a vedação à coordenação das empresas e o acesso a informações comercialmente sensíveis durante o período que antecede a aprovação do ato de concentração, prevista no art. 88 da Lei 12.529 , encontra uma justificativa concreta, demonstrável a partir da teoria dos jogos.

A teoria dos jogos, e notadamente a análise do modelo de duopólio de Cournot, comprova o efeito nocivo que a coordenação de empresas pode produzir no mercado: a elevação dos preços, em detrimento dos consumidores, cujos interesses, por determinação constitucional, devem ser tutelados, sendo este um dos pilares da Ordem Econômica. 
Nessa linha de ideias, as proibições de coordenação de condutas impostas às empresas envolvidas em um ato de concentração, previstas pela nova Lei Antitruste, com vistas a impedir a consumação prematura do ato (gun jumping), encontram razão de ser no fato de que em sua ausência os preços seriam mais elevados, em prejuízo da concorrência e do consumidor.

\section{CONCLUSÃO}

A partir dos casos apresentados, pretendeu-se demonstrar a importância da análise sobre as possíveis decisões de todos os agentes, partindo de modelos propostos pela teoria dos jogos, para que se possa alcançar os objetivos pretendidos por uma determinada decisão de caráter jurídico. Seja no momento da decisão sobre a estrutura legislativa - estabelecendo-se os direitos de propriedade intelectual ou, ainda, a estrutura de análise de atos de concentração, como nos casos apresentados nesse artigo - ou, posteriormente, durante a escolha de aplicação do direito durante uma decisão judicial - não analisada nesse artigo - compreender os efeitos que se pretende e os possíveis ganhos dos agentes que se pretende alcançar é fundamental para o planejamento de estratégias que consigam alcançar os objetivos propostos.

Assim, a teoria dos jogos ganha importância enquanto ferramental que permite que o direito seja compreendido como um 'jogo’ (no conceito da teoria dos jogos), sendo possível desviar a ação dos agentes para aquela que se pretende, em geral tendo em vista uma conduta mais benéfica para a sociedade. A partir daí, é possível determinar regras específicas para cada 'jogo' que permitam a maior quantidade de benefícios sociais líquidos, recompensando positivamente as ações que se espera, e penalizando as ações que vão de encontro aos objetivos pretendidos, por exemplo.

Mais do que apresentar uma solução única ou infalível, pretendeu-se demonstrar com o presente artigo que a utilização da teoria dos jogos pode ser uma ferramenta fundamental no Estado Democrático de Direito como meio de se alcançar, de forma efetiva e eficiente, as finalidades que se pretende, desde a norma até a decisão judicial. A partir daí, pretendeu-se incluir esse ferramental no arcabouço disponível ao profissional do direito, para que, com os demais elementos disponíveis em sua tomada de decisão, possa caminhar no sentido de tomar as decisões mais eficientes e eficazes possíveis para atingir os objetivos pretendidos. 


\section{REFERÊNCIAS}

BIERMAN, Scott H.; FERNANDEZ, Luiz. Teoria dos Jogos. $2^{\text {a }}$ Ed. São Paulo: Ed. Pearson Prentice Hall, 2011. 413p.

BRASIL. Lei n 12.529/11, de 30 de novembro de 2011. Planalto. Disponível em <http://www.planalto.gov.br/CCIVIL_03/_Ato2011-2014/2011/Lei/L12529.htm>. Acesso em 22 de agosto de 2015.

CARRARO, André. Propriedade Intelectual e Teoria dos Jogos. $1^{\text {a }}$ Ed. Santa Cruz do Sul: EDUNISC, 2005. 96p.

CONSELHO ADMINISTRATIVO DE DIREITO DA CONCORRÊNCIA - CADE. Guia Prático do CADE: a defesa da concorrência no Brasil. $3^{\text {a }}$ Ed revista, ampliada e bilíngue. São Paulo: CIEE, 2007. Disponível em $\langle$ http://www.cade.gov.br/publicacoes/guia_cade_3d_100108.pdf $>$. Acesso em 15 de agosto de 2015.

CONSELHO ADMINISTRATIVO DE DIREITO DA CONCORRÊNCIA - CADE. Resolução $n^{\circ}$ 20, de 9 de junho de 1999 - Anexo I. Diário Oficial da União de 28 de junho de 1999. Disponível em <http://www.cade.gov.br/upload/Resolu\%C3\%A7\%C3\%A3o\%20n\%C2\%BA\%2020,\%20de $\% 209 \% 20 \mathrm{de} \% 20 \mathrm{junho} \% 20 \mathrm{de} \% 201999 . \mathrm{pdf}>$. Acesso em 15 de agosto de 2015.

. CADE. Resolução $n^{o} 1$, de 29 de maio de 2012. Diário Oficial da União de 31 de maio de 2012, nº105, sessão1, páginas 77 a 88.

COOTER, Robert; ULEN, Thomas. Law \& Economics. 5 ${ }^{\text {a }}$ Ed. Pearson Addison-Wesley, 2008. 582p.

CORDOVIL, Leonor. et al. Nova lei de Defesa da Concorrência comentada: Lei $n^{\circ} 12.529$ de 30 de novembro de 2011. $1^{\text {a }}$ Ed. São Paulo: Ed. Revista dos Tribunais, 2011. 229p.

FIANI, Ronaldo. TEORIA DOS JOGOS. Rio de Janeiro: Elsevier, 2009.

LARA, Fabiano Teodoro de Rezende. Propriedade Intelectual: Uma abordagem pela análise econômica do direito. $1^{\mathrm{a}}$. Ed. Belo Horizonte: Del Rey, 2010. 140p.

MARTINS, Amanda A. L. Gun Jumping no Brasil: estudo comparativo e diretrizes para a adoção de regras de notificação prévia pelo Novo CADE. Revista do IBRAC. São Paulo, n. ${ }^{\circ}$ 22, julho-dezembro 2012. 
SILVA, Leandro Novais e. Propriedade Intelectual e Direito Antitruste: a velha e a nova economia em disputa. Publicações da Escola da AGU, v. 2, p. 143-170, 2012. 